\title{
Evolving sustainable environmental sanitation behaviour among secondary school students: home and school as correlated in Ogbomoso, Nigeria
}

\author{
A. O. Afon, S. A. Okanlawon, F. O. Adigun \& O. O. Odunola \\ Ladoke Akintola University of Technology, Ogbomoso, Nigeria
}

\begin{abstract}
This study examined the potential influence of homes and schools on evolving sustainable sanitation behaviour among secondary school students in Ogbomoso, Nigeria. Data for the study were obtained from 379 systematically selected students from the three generations of stratified schools in the town. Findings conclude that the students' knowledge on what constitutes ideal sanitation behaviour was high enough. However, the physical amenities through which the knowledge can be practiced were grossly inadequate both at students' homes and schools. The inadequacies were both quantitative and qualitative. The inadequacies of sanitation became clear in the students' responses; some of which the teachers and parents might have been practising. The study concluded that for homes and schools to act as correlates of evolving sustainable sanitation behaviour among these future adults, teaching on how to develop good hygiene behaviour must be matched with corresponding provision of environmental sanitation amenities.

Keywords: school sanitation, secondary school, sanitation behavior, home, students, sanitation amenities, Ogbomoso, Nigeria, sustainable sanitation, waste disposal.
\end{abstract}

\section{Introduction}

The central thesis of this paper is that neither the provision of sanitation facilities without appropriate hygiene behaviour, nor the teaching of how to develop good hygiene behaviour, without corresponding physical provision of amenities, will 
result in sustainable environmental sanitation. From this point of view, environmental sanitation conditions are highly modified by the development of related appropriate knowledge (predisposing factor) by residents and the provision of adequate physical facilities (enabling factor).

People of all ages among urban populations should be provided with both adequate hygiene knowledge and environmental sanitation hardware. One of the most important age groups that need exposure to good environmental sanitation practices are secondary school students, and homes and schools play an important role in reinforcing the enabling factors. A cursory glance at the sanitation condition of Nigerian cities revealed nothing but a sorry state [1]. There is also documented evidence that Nigerians' sanitation knowledge and behaviour are bad [2]. Indeed, this was so noticeable that the federal government of Nigeria enacted a decree in 1983 establishing a compulsory monthly environmental sanitation exercise from the hours of $7.00-10.00$ a.m. on the last Saturday of every month [3]. When it was discovered that the exercise was of great futility, and mere wasting of citizens' time, the exercise was cancelled in 1999. This was at the inception of democratic governance. The purpose for which it was established - fostering a better environmental behaviour, was not achieved. Yet, this is the bedrock upon which sustainable sanitation can be built.

One of the ways through which the authors of this paper thought this can evolve is the examination of the relevance of home and school and their influence in helping to modify the behaviour of, would be, tomorrow's adults. The students of selected secondary schools in Ogbomoso, Oyo State, Nigeria were used as a case study.

This study is an attempt to provide answers to questions such as: What is the level of health education attained by students? What are the sanitation amenities available for use by students at homes and schools? What are the students' responses to the adequacy of the amenities? And what are the implications of these on evolving sustainable sanitation behaviour among these future adults?

\section{Issues in environmental sanitation in relation to school children}

The World Health Organizations (WHO) [4] defined sanitation as the promotion of hygiene behaviour and the prevention of disease and other consequences of ill-health, relating to environmental factors. It is a measure taken to protect public health through proper solid waste disposal, sewage disposal and cleanliness during food processing and preparation [5]. It also involves the maintenance of public health and hygiene, especially the water supply, sewage systems, sewage and garbage collection and disposal.

Environmental sanitation covers two main basic dimensions [5]. The first entails the activities to control environmental factors that impact on the infestations agents and transmission of diseases. It directly involves the construction and provision of environmental sanitation physical amenities like toilets, drainage, solid waste and waste water management among others. The second dimension involves the development of good hygiene behaviour among 
residents. It therefore follows that a sustainable environmental sanitation solution cannot evolve through the mere provision of facilities; rather, in addition, related appropriate hygiene behaviour should be developed among and by people [5].

That environmental sanitation is the bedrock of overall development of a nation is succinctly pointed out [6] due to its identified importance. These include that sanitation is vital for human health; good for economic growth and poverty reduction; helps the environment; contributes to social development and above all, affects children's development and future. Despite these identified unique importance, it is recorded that about 2.4 billion people of the world remain without access to basic sanitation [7]. Majority of this figure are known to be residing in the developing world.

The problems of evolving sustainable environmental sanitation practices especially in developing countries and Nigeria in particular are two fold. These are the lack of basic sanitation amenities and poor sanitation habits [8]. These conditions become more worrisome if serious consideration is given in terms of the future. This is because the children, tomorrow's adults, are clearly engulfed in the mess of being exposed to far from the ideal sanitation amenities and related appropriate hygiene behaviour. And the importance that development has, through the active participation of children, especially on sanitation, has been severally identified and appreciated.

It is generally recognized that childhood is the best time for children to learn hygiene behaviour. Children are future parents and what they learn is likely to be applied in the rest of their lives [5]. At the same time, children have important roles in the household. They become agents of change within their families and a stimulus to community development. Being tomorrow's parents, children are likely to ensure the sustainability of a programme's impact.

To evolve sustainable sanitation behaviour among children, it is observed that several organisations have roles to play. These include the government, society, mass media, homes and schools [9]. Of importance to this study are the roles that homes and schools can play on children's environmental sanitation behaviour [5].

The importance of schools in evolving sustainable hygiene behaviour in future leaders has been identified [10]. As observed, it is important to focus on schools because they have a central place in the community. If sanitary facilities are available in schools, they can act as a model and teachers can function as role models [5]. Schools can also influence communities through outreach activities. This is because, through students, schools are in touch with a large proportion of the households in a community [18]. It is also appreciated that if school sanitation and hygiene facilities are absent, or are badly maintained and used, schools become places where diseases are transmitted. Schools can also pollute the natural environment in such a way that it causes health hazards for the community at large [11]. This position stresses the importance of schools to have proper facilities. A caution was also added that if incidence of sanitation and hygiene related diseases are to be reduced; and the natural environment to be protected; the provision of proper facilities is not enough. Behavioural changes are also needed $[5,7]$. 
Comments on the importance of homes as an instigator of evolving sustainable sanitation behaviour are also available. In the first place, children spend longer periods of time in their homes than schools for children who are not residents of their various schools. On the other hand, students have the opportunities of practicing what they learnt in schools at homes especially during the holidays. Thus, it follows that the environmental sanitation amenities available for use at home and the level of sanitation education and hygiene behaviour of parents come to impact on the children very highly [5].

In general, to evolve lasting change in hygiene behaviour of school children, three factors are to be identified by both the home and school [5]. These factors are:

a) Predisposing factors - These factors include the knowledge, attitude and belief impacted on students on environmental sanitation;

b) Enabling factors - These involve the availability of resources like latrine facilities and safe water supply, enabling students to transform newly acquired knowledge, attitude and belief into desirable behaviours; and,

c) Reinforcing factors - These are the factors affecting the students' ability to sustain certain behaviour like support and cooperation from parents, guardians, peer groups and teachers. From the above, increasing students' knowledge about health and disease prevention is not the total story. Knowledge impacted by home and school should be supported by enabling and reinforcing factors if desirable change will occur in the school setting and in the community, especially in the future. This stresses the importance of combining hygiene education with the construction of water and sanitation facilities involving the community and health institutions. The question that this study will like to answer is how has the home and school be fairing at evolving sustainable sanitation behaviour among selected secondary students based on predisposing, enabling and reinforcing factors?

\section{Physical setting of the study}

The study area is the selected secondary schools in Ogbomoso, Oyo State, Nigeria. The secondary schools in Ogbomoso could be grouped into three generations. The first generation are schools established prior to 1979 when schools were taken over by the government. The second generation are schools established between 1979 and 1999 when democratic governance was in place. Schools established after 1999 to date are in the third generation. Preliminary survey revealed that there were four, eighteen and fifteen schools respectively in the first, second and third generations. Grouping these into ownership, it is established that one, twenty and fifteen were respectfully owned by the federal and state governments, and private individuals and organizations respectively. It was discovered that sanitation amenities were in different states of dilapidation in these schools. 


\section{Methodology}

The data for the study were obtained from students in the three categories of schools. The schools were selected in a way that three ownerships were represented. Fifty percent of the first generation secondary schools were selected for study (one federal and one state government owned school). Because of the numbers, thirty percent of the schools in the second and third generations were studied. In this regard, five and six schools respectively were surveyed among the second and third generation schools. Their selection was based on random without replacement. A student was selected systematically for questionnaire administration out of every twenty students. Using the above methodology, a total of 379 students were surveyed in all the schools. A breakdown indicated that 155, 142 and 82 students were sampled respectively in the first, second and third generation schools.

Information obtained from students include the sanitation amenities available in their schools and homes; their responses to level of availability of these amenities both at home and schools. In addition, existing physical infrastructure in schools physically were examined.

\section{Research findings}

The research findings are as summarized below. The source of all tables in this section is from the authors' survey of November/December, 2007.

The students' knowledge on what constitutes good environmental sanitation behaviour was examined on the basis of the three generations to which the secondary schools in the town were stratified. Presented in Table 1 is the proportion of the students that correctly provided answers to questions testing their understanding on simple principles of hygiene. It is established that students in all the three categories of schools had a fairly good theoretical knowledge of what good hygienic behaviours are. It is observable from the table that not less than $60 \%$ of students in all the schools provided correct answer to the questions asked. A higher proportion of students in the third generation school however provided correct answers to these questions. Further, an examination on how the educational background of students could affect students' responses was done. The study established that as the educational status of parents is increasing, students' knowledge on what constitutes good environmental sanitation behaviour was also increasing. Confirming this is the fact that $39.4 \%, 21.1 \%$ and $46.3 \%$ of the students' fathers had university education respectively in the first, second and third generation schools. Similarly, $24.6 \%, 13.9 \%$ and $36.6 \%$ of mothers in these respective schools were with first degree certificate. It is therefore conclusive that students in secondary schools in the study area were exposed to the predisposing factors in environmental sanitation. This is one of the good factors that can ensure sustainable environmental sanitation behaviour in these adults of the future. 
Table 1: $\quad$ Percentage of students that correctly provided answers to questions testing knowledge on hygiene in different schools.

\begin{tabular}{|l|c|c|c|c|}
\hline \multicolumn{1}{|c|}{ Hygiene knowledge } & First & Second & Third & All schools \\
\hline $\begin{array}{l}\text { It is good that standing water be } \\
\text { allowed near our houses? }\end{array}$ & 69.7 & 69.0 & 96.3 & 75.2 \\
\hline $\begin{array}{l}\text { Street littering is very } \\
\text { dangerous to our health }\end{array}$ & 62.6 & 62.7 & 97.6 & 70.2 \\
\hline $\begin{array}{l}\text { Passing urine and stools in open } \\
\text { areas at schools and homes is } \\
\text { not a bad practice }\end{array}$ & 66.5 & 71.1 & 95.1 & 74.4 \\
\hline $\begin{array}{l}\text { Our toilets must be kept clean } \\
\text { to keep away flies }\end{array}$ & 89.0 & 87.3 & 100 & 90.8 \\
\hline $\begin{array}{l}\text { A good ventilations helps to } \\
\text { prevent the spread of catarrh } \\
\text { and cough }\end{array}$ & 60.0 & 60.6 & 84.1 & 65.4 \\
\hline $\begin{array}{l}\text { We should wash our hands } \\
\text { immediately we are out of } \\
\text { toilets }\end{array}$ & 78.1 & 79.6 & 93.9 & 82.1 \\
\hline $\mathrm{N}$ & 155 & 142 & 82 & 379 \\
\hline
\end{tabular}

Table 2: Percentage of students with accessibility to hardware sanitation facilities at schools.

\begin{tabular}{|l|c|c|c|c|}
\hline Sanitation facilities & First & Second & Third & All schools \\
\hline Pit toilet & 49 & 40.1 & 51.2 & 46.2 \\
\hline Water closet & - & - & 45.1 & 9.8 \\
\hline Tap water & 2.6 & 5.7 & 6.1 & 4.5 \\
\hline Well water & 51.6 & 69.0 & 82.9 & 64.9 \\
\hline Bore hole & - & - & 65.9 & 332 \\
\hline Waste water pit & 18.7 & 16.9 & 20.1 & 18.5 \\
\hline Waste storage container & 9.7 & 9.2 & 29.3 & 13.7 \\
\hline Wash hand basin & 39.4 & 17.6 & 63.3 & 37.5 \\
\hline $\begin{array}{l}\text { Government waste collection } \\
\text { service }\end{array}$ & - & - & - & - \\
\hline $\begin{array}{l}\text { Separate toilet for male and } \\
\text { female }\end{array}$ & 67.1 & 53.5 & 91.3 & 67.2 \\
\hline
\end{tabular}

To evaluate the enabling factors (the hardware) that make students to put the knowledge gained into practice, an assessment of the students' accessibility to environmental sanitation facilities in schools and homes was carried out. The findings were as summarized in Tables 2 and 3.

A cursory glance at the table indicated that less than half of the students in the first and second generation schools (owned by either the state or federal governments) had access to vital sanitation amenities. For example, only $49.3 \%$ of the students claimed that they had access to pit toilet in the first generation 
school. The proportion of students in this category was $40.1 \%$ in the second generation. And indeed, access to pipe borne water was very low in all the three categories of schools. No students in the first and second generations schools had access to pipe borne water and water closet. While only $9.8 \%$ had access to pipe borne water in the third generation schools $45.1 \%$ had access to water closet. The most popular source of water supply was wells. This accounted for $51.6 \%$, $69.0 \%$ and $82.9 \%$ in the first, second and third generation schools respectively. In all the schools, $67.2 \%$ of the students indicated that provision was made for separate toilets for male and female gender.

Environmental sanitation amenity provision in students' homes was not significantly different from that of the schools. As summarized in Table 3, $39.4 \%, 47.9 \%$ and $19.5 \%$ of the students respectively in the first, second and third generations schools had pit toilets in their homes. On the other hand, $52.3 \%, 31.9 \%$ and $74.4 \%$ of the students had access to water closet respectively in their homes as well. From these findings, it was evident that there were homes where toilet facility was not provided. The most popular water supply system was through wells. It represented $67.0 \%$ in all the homes.

Considering the inadequacy in the provision of environmental sanitation facilities at homes and schools, despite the knowledge gained by students, their responses to meeting the needs of two critical elements of sanitation (toilets and waste disposal) were examined.

Investigation revealed that students' responses as presented in Table 4 to inadequate toilet at homes and schools were not environmentally friendly.

A critical examination further revealed that some students, despite the fact that facilities were available in their schools and homes, engaged in an environmentally unfriendly behaviour of urinating and defecating as identified in Table 4. Presented in Table 5 are the proportion of students indicating different reasons why they were not making use of toilet facilities at homes and schools. The reasons why students were not making use of toilets at home and schools can be summarized as that the toilets were not well kept.

Table 3: Percentage of students with accessibility to hardware sanitation facilities at home.

\begin{tabular}{|l|c|c|c|c|}
\hline Sanitation facilities & First & Second & Third & All schools \\
\hline Pit toilet & 39.4 & 47.9 & 19.5 & 36.3 \\
\hline Water closet & 52.3 & 31.9 & 74.4 & 49.1 \\
\hline Tap water & 13 & 9.1 & 15.0 & 10.0 \\
\hline Well water & 66.5 & 60.6 & 79.3 & 67.0 \\
\hline Bore hole & 5.2 & 3.5 & 25.6 & 9.0 \\
\hline Waste water pit & 44.5 & 18.3 & 85.4 & 43.5 \\
\hline Waste storage container & 33.5 & 21.8 & 74.4 & 38.0 \\
\hline Wash hand basin & 12.3 & 6.3 & 14.6 & 7.9 \\
\hline $\begin{array}{l}\text { Government waste collection } \\
\text { service }\end{array}$ & - & - & - & - \\
\hline $\mathrm{N}$ & 155 & 142 & 82 & 379 \\
\hline
\end{tabular}


Table 4: Students' responses to inadequate toilet facility at home and school.

\begin{tabular}{|l|c|c|}
\hline Reasons & Home & School \\
\hline Defecating and urinating in open areas & 24.3 & 27.4 \\
\hline Defecating and urinating outside the fence & 14.0 & 21.7 \\
\hline Defecating and urinating in near by bush & 42.1 & 64.9 \\
\hline $\begin{array}{l}\text { Defecating and urinating in cans, nylon and } \\
\text { polythene materials and thrown indiscriminately }\end{array}$ & 68.4 & 14.2 \\
\hline Defecating at back of the toilet & 8.5 & 20.5 \\
\hline Defecating on toilet floor & 24.8 & 11.9 \\
\hline $\begin{array}{l}\text { Defecating and urinating in dilapidated buildings } \\
\text { around }\end{array}$ & 17.2 & 9.2 \\
\hline $\begin{array}{l}\text { Defecating and urinating in buildings under } \\
\text { construction }\end{array}$ & 3.6 & 5.3 \\
\hline $\mathrm{N}$ & 379 & 379 \\
\hline
\end{tabular}

Table 5: $\quad$ Percentage distribution of students giving different reasons for not using toilet facility at home and school.

\begin{tabular}{|l|c|c|}
\hline Reasons & Home & School \\
\hline Toilet floor is soiled with excreta & 15.1 & 16.6 \\
\hline Toilet is filled up & 20.3 & 12.9 \\
\hline Waste paper littered the toilet floor & 13.7 & 15.8 \\
\hline The toilet is usually in lock & 25.3 & 13.7 \\
\hline Fear that the toilet building can collapse & 5.8 & 7.1 \\
\hline Toilet is exclusively for the adult & 8.4 & 15.0 \\
\hline Poor ventilation & 10.0 & 10.0 \\
\hline Instructed not to use school toilet & - & 12.4 \\
\hline No water to use in the toilet & 11.1 & 10.8 \\
\hline Lack of privacy & 9.2 & 9.8 \\
\hline Fear that one way contact disease & 15.6 & 17.8 \\
\hline
\end{tabular}

It was further identified that students used a range of materials to clean themselves after defecation. The proportions of students using water at home and school respectively were $74.4 \%$ and $41.2 \%$; toilet rolls $(12.9 \%, 4.5 \%)$; paper $(36.4 \%, 12.9 \%)$; leaf $(0.3 \%, 3.4 \%)$ and nothing $(2.9 \%, 1.8 \%)$.

The second critical issue in environmental sanitation examined was the waste disposal behaviour of the students. The study established that in the absence of government and private sector participation in solid waste collection service, the wide range of methods of disposal practices in all the schools were not sanitary. As it could be obtained from the summary presented in Table 6, nine methods of waste disposal were identified in the students' homes while five were employed in schools. Since a combination of these methods were employed, the proportion of each method relative to all was computed as shown in Table 6. From the above, it is deducible that while burning constituted $22.0 \%$ of the methods of waste disposal method in the students' homes, the same 
accounted for $49.4 \%$ at school. The use of open pit to dispose waste ranked second in schools; where as, dumping of waste in dilapidated buildings was second in importance at home. It is conclusive that the various methods of waste disposal to which students were exposed at home and school were not environmentally sustainable.

Table 6: $\quad$ Solid waste disposal methods at home and school.

\begin{tabular}{|l|c|c|}
\hline Disposal Methods & Home & School \\
\hline Burning & & \\
\hline Open dump site & 12.6 & 13.1 \\
\hline Burying & 1.0 & 8.8 \\
\hline Open pit & 1.1 & 23.9 \\
\hline Inside drain & 15.0 & - \\
\hline Outside the fence & 9.0 & 4.8 \\
\hline Dilapidated building & 18.5 & - \\
\hline Building under construction & 11.0 & - \\
\hline Vacant land & 9.9 & - \\
\hline Total & 100 & 100 \\
\hline
\end{tabular}

\section{Conclusion}

The study established that students had acquired an appreciable knowledge, attitude and beliefs than can evolve into sustainable environmental sanitation behaviour. In other words, the predisposing factors that students had already gained can lead to sustainable environmental sanitation behaviour. There was, however, inadequate provision of the environmental sanitation hardware (facilities) both at homes and schools. It is not out of place to conclude that teachers and parents will be engaging in unsanitary means of defecating, urinating and disposing of solid waste. The study has therefore demonstrated that while students' knowledge about health and disease prevention is high, this has not been supported by enabling and reinforcing factors either at home or at school. To this end, desirable changes will not occur in schools and in the community; hence, sustainable environmental sanitation practices cannot evolve from among students who consequently hold the future. The study concludes that in order to evolve a sustainable environmental sanitation practice among students, it is imperative that the provision of environmental sanitation hardware should be sped up.

It was identified that schools owned especially by the state government were mostly affected by disrepair states of sanitation amenities. Evidence abounds that facilities in the first generation schools showed that those facilities were provided before the schools were taken over by the government in 1979 . However, because of the free-education policy, these amenities were not maintained for lack of funds and corruption. While these amenities were not provided in many of the second generation schools, proper maintenance was not embarked upon to put these amenities in sanitary condition in very many of the 
schools. The problem in government schools is compounded by the fact that the agency to regulate sanitation in schools was owned by the government. As a result, to make sure private schools provide necessary sanitation amenities becomes more problematic when government schools were in state of disrepair. When a comparative analysis is made of the facilities available in the privately owned schools and the government schools, it is established that private schools are better provided with sanitation amenities. Therefore, to actually improve the sanitation facilities in Nigerian secondary schools with the objective of impacting positively in the behaviour of students, schools owned by government should be models. With this in place, it can be enforced on private schools to equip them to the standard of the government schools.

Improvement should also be made in the provision of sanitation amenities in the residential environmental. However, to enforce compliance on parents becomes a very great task since government on its part had failed to provide basic facilities like water, public toilets, waste refuse management services among others. All these encouraged residents (parents) to develop responses that are not environmentally sustainable. Invariably, students are also developing these unsanitary behaviours. Thus, the school and home have great roles to play in evolving sustainable environmental sanitation practice among students through the provision of physical facilities.

\section{References}

[1] Osuntogun, A., Poverty, Health and the Nigerian environment. Lagos, FEDEN, 1998.

[2] Afon A.O., Solid waste management in selected cities of Oyo State, Nigeria. Ph.D. dissertation, Department of Urban and Regional Planning, Obafemi Awolowo University, Ile-Ife, Nigeria, 2005

[3] Federal Republic of Nigeria, Environment sanitation edict. Lagos, Federal Government Press, (1983)

[4] World Health Organization (WHO), Environmental matters: strategy on sanitation for high risk communities. Report by the Director General to the Executive Board, Geneva, 1997.

[5] Protos Uganda, Preliminary literature study to a school sanitation and hygiene strategy www.protos.be, 2005.

[6] Robinson, A., Universal sanitation in East Asia: mission possible? Background document and thought piece for the $1^{\text {st }}$ East Asia Ministerial Conference on Sanitation and Hygiene held in Bappu City; Japan, 2007

[7] World Bank, World Development Report. New York; Oxford University Press, (2005).

[8] Afon A.O., The use of residents' satisfaction index in selective rehabilitation of urban core residential areas in developing countries. International Review for Environmental Strategies, 6(1), pp.137-152, 2006.

[9] Bundy, D. A. P., \& Guyatt H. C., Schools for health: forces on health education on the school age. Child Parasitology Today 12, pp. 1-16, 1996. 
[10] UNICEF, Progress for children: a report card on water and sanitation. New York, UNICEF, 2006.

[11] Ebong, R. D., Environmental health knowledge and practice survey among secondary school children in Zaria, Nigeria. Environmental Health Perspective, 102, pp. $1-4$. 